\title{
Carotid Artery Disorder
}

National Cancer Institute

\section{Source}

National Cancer Institute. Carotid Artery Disorder. NCI Thesaurus. Code C84476.

A non-neoplastic or neoplastic disorder affecting the carotid artery. 